\title{
Assessment of post-traumatic amnesia after severe closed head injury: retrospective or prospective?
}

\author{
T M McMillan, E L M M Jongen, R J Greenwood
}

\begin{abstract}
Background-Post-traumatic amnesia is considered to be the best single indicator of the severity of closed head injury. Usually, it has been estimated retrospectively. For practical reasons this also tends to be the most common clinical method. It has been argued that prospective assessment is more accurate and reliable, but this has never been evaluated empirically in severe head injury.

Methods-Post-traumatic amnesia was initially assessed prospectively and later retrospectively by a separate observer in the same patients.

Results-The correlation between the two methods was high. In addition, both measures significantly correlated with other measures of severity of brain injury and with measures of outcome.

Conclusion-Retrospective measurement of post-traumatic amnesia is a valid method.
\end{abstract}

(F Neurol Neurosurg Psychiatry 1996;60:422-427)

Keywords: post-traumatic amnesia; retrospective assessment; prospective assessment

Advances in neuroimaging techniques have not diminished the importance of behavioural measures in assessing severity and predicting outcome after closed head injury. Since 1932, when Russell proposed that the sum of the comatose and confusional periods would be the most useful predictor of outcome, ${ }^{1}$ many studies have shown that the duration of posttraumatic amnesia still provides the "best yardstick we have", ${ }^{2}$ better, for example, than the depth or duration of coma or changes on acute MRI. ${ }^{3-7}$

In most studies the duration of post-trau-

Department of Clinical Neuropsychology, Wolfson Rehabilitation Centre, Atkinson Morley's Hospital, Morley's Hospital, Trust, London, UK T M McMillan

Department of Neurological Sciences, St Bartholomew's Hospital, London, UK E L M M Jongen R J Greenwood

Correspondence to: Dr T M McMillan.

Received 22 February 1995 and in final revised form 21 November 1995 Accepted 29 November 1995 of retrospective assessment of post-traumatic amnesia remains unknown. There may be sigduration of post-traumatic amnesia. ${ }^{9}$ ory returns is often difficult to specify objeccrepancies in studies relating post-traumatic amnesia to outcome. ${ }^{8}$ The time between loss of consciousness and return of continuous nificant variation in estimates obtained on different occasions, or by different interviewers. The clinician relies on the patient's own judgement and the relatives' memory for events; the second often being associated with great stress, which could render such memories unreliable. In the patient, confabulations can occur after traumatic brain injury, or the patient may attempt to reconstruct events, partly from accounts related by others rather than from their own recall of events. Assessment is further complicated by the presence of islands of intact memory in an otherwise amnesic period. These can be mistaken for the end of post-traumatic amnesia..$^{910}$

Many of these difficulties might be avoided by prospective measurement of post-traumatic amnesia. Some measures have been developed, such as the Galveston orientation and amnesia test (GOAT), ${ }^{11}$ the Westmead posttraumatic amnesia scale, ${ }^{4}$ and the Julia Farr Centre post-traumatic amnesia scale. ${ }^{8}$ Some authors claim that prospective measures of the duration of post-traumatic amnesia are likely to be more accurate and more reliable in estimating the severity of brain damage and thus in relating post-traumatic amnesia to outcome. ${ }^{8}$ However, there is no convincing evidence to support this view because prospective and retrospective methods have never been compared systematically in the same investigation. One study showed a significant correlation between results obtained from a precursor of the Westmead post-traumatic amnesia scale and as separately estimated by neurosurgeons on the ward using a qualitative method (interview); both were estimated near to the time of injury. ${ }^{12}$ Gronwall and Wrightson ${ }^{13}$ prospectively assessed post-traumatic amnesia in very minor head injury $(80 \%$ of the 67 patients had post-traumatic amnesia for less than one hour). They included a retrospective assessment between one week and three months after injury to determine the consistency of the patient's response, rather than to look at the validity of a retrospective technique itself. The assessor was not blind to the original assessments. They did not find statistical differences in duration of post-traumatic amnesia between prospective and retrospective measures. Correlations are not reported. As post-traumatic amnesia is difficult to assess when injury is so mild, the relevance of this work to patients with severe head injury is not clear. In the present study we compared the duration of post-traumatic amnesia assessed prospectively using the GOAT and retrospectively at interview between 3.5 and six years after injury. 


\section{Methods}

Consecutive patients who sustained a severe closed head injury and who were admitted to one of two university hospitals or four district general hospitals in north London, were initially entered in the study between March 1988 and November 1990 . They are described in detail elsewhere ${ }^{14}$ and had either been in a coma for more than six hours or had a posttraumatic amnesia of 48 hours or more. If in the previous year patients had received hospital treatment for drug or alcohol misuse, psychiatric disturbance, or an organic disorder of the CNS, they were excluded. On recruitment, severity of injury was rated using the admission Glasgow coma scale score, ${ }^{15}$ number of days in coma, and the duration of posttraumatic amnesia as measured by the GOAT (appendix 1). The GOAT was given when the patient was able to cooperate and was repeated daily until the score increased to $75 / 100$ or more for three successive days. ${ }^{11}$ Duration of post-traumatic amnesia was defined as the interval between injury and obtaining a "normal" score on the GOAT.

Patients were followed up between March and May 1994, some 3.5 to six years after injury, when the duration of post-traumatic amnesia was determined retrospectively by telephone interview with the patient. The duration of post-traumatic amnesia was taken to be the interval between injury and the patient regaining continuous memory for day to day events. The interview was structured by using notes in hospital records and dates of special events to establish landmarks in the acute stage after the head injury (appendix 2). The interviewer (ELMMJ) was a medical student without previous clinical experience of patients with head injury and who was trained and supervised by the authors in the retrospective assessment of post-traumatic amnesia for the purpose of the study. The GOAT data were kept in research files, separate from hospital records, and were not available to the interviewer until after the retrospective data had been collected. The interviewer was thus blind to the prospective estimate of duration of post-traumatic amnesia until after the interviews.

Data from the same patients were then used to compare the durations of post-traumatic amnesia as estimated prospectively using the GOAT and retrospectively by telephone interview. Further comparisons were also made after classifications of post-traumatic amnesia into "severity" categories: (a) the three banded classification is perhaps the most widely used and was first described by Russell, ${ }^{1}$ and later extended by Jennett and Teasdale ${ }^{15}$; $(b)$ the

Table 1 Classifications of severity of closed head injury into bands using duration of posttraumatic anaemia

\begin{tabular}{lll}
\hline (A) Russell': fennett and Teasdale & (B) Van Zomeren and Van Den Burg' & (C) 5 band \\
\hline $1-7$ days severe & $1-13$ days severe & $<2$ weeks \\
$1-4$ weeks very severe & $>13$ days very severe & $>2$ weeks \\
$>4$ weeks extremely severe & & $>1$ month \\
& & $>3$ months \\
& $>6$ months \\
\hline
\end{tabular}

dichotomy proposed by Van Zomeren and Van Den Burg ${ }^{16}$ who found that outcome is poorer when post-traumatic amnesia is greater than 13 days; (c) an unvalidated five band classification using the principles underpinning $(a)$ and $(b)$, but further subdividing posttraumatic amnesia durations of more than four weeks on the basis of the clinical finding that patients who have a post-traumatic amnesia of one to three months may achieve supported but not independent employment, after a post-traumatic amnesia of three to six months they may achieve independence in the community, and with post-traumatic amnesia greater than six months, independence in the community is unusual (table 1).

A questionaire relating to psychosocial outcome was devised partly from those of another study, using questions found to be sensitive to outcome $^{14}$ (available from the authors on request). The questionaire was given retrospectively as a part of the telephone interview of patients and relatives.

\section{Results}

Of the 126 patients recruited into the original study, 108 had been followed up for at least six months. ${ }^{14}$ In the present study 79 of these were traceable $(73 \%)$. In 12 of the 79 the interviewer was unable to define posttraumatic amnesia exactly, and their results are only included in analyses in which posttraumatic amnesia is classified into "bands" (table 1). In one other case post-traumatic amnesia had not ended by the end of the original study.

Of these 79 patients, 54 were men and 25 were women. Their mean age at the time of injury was $29 \cdot 2$ (SD 13.1); range $16-58$ years. The duration of coma ranged from 0 (that is, 6 to 23 hours) to 72 (mean $8 \cdot 3$ (SD 11.8 )) days. On admission $50.0 \%$ of the subjects had a low score on the Glasgow coma scale (3-5), 27.6\% scored $6-8$, and $22 \cdot 4 \%$ scored $9-15$. The duration of post-traumatic amnesia measured prospectively by GOAT ranged from 2 to 185 , mean 34.3 (SD 41.7 ) days, median 20 days. The duration of post-traumatic amnesia estimated retrospectively ranged from less than 24 hours to 244 , mean 38.9 (SD 50.8 ), median 15 days.

Comparisons were made between the patients who were traceable at the current follow up and the remainder to check for any bias. Common data were found for 76 of the traceable patients and 37 of the remainder from the overall sample of 126 . Differences were not statistically significant between these two groups for age, sex, days loss of consciousness, Glasgow coma scale score, or the prospective measure of duration of post-traumatic amnesia $(P>0.05)$. This suggests that the "untraceable" patients did not represent any discrete subgroup of the overall sample in terms of demography or severity of head injury.

Figures 1 and 2 are scatterplots of individual patients. Figure 1 shows all patients and fig 2 shows the relation between prospective and 
Figure 1 Association between prospective and retrospective measures of post-traumatic amnesia for all patients.

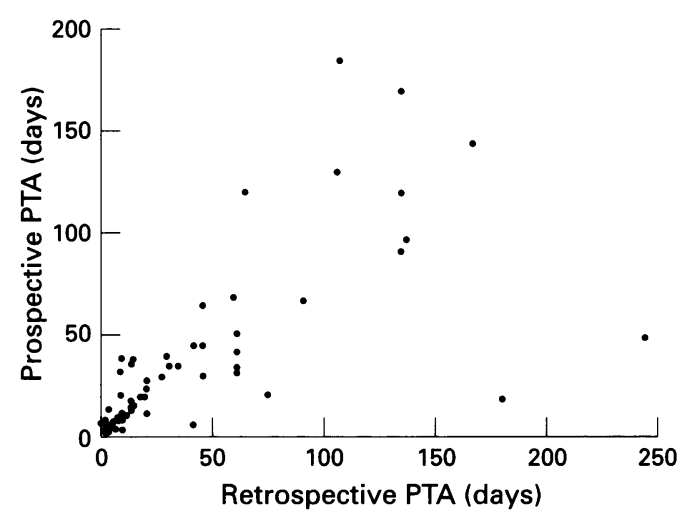

Figure 2 Association between prospective and retrospective measures for patients with postdays. traumatic amnesia $<60$

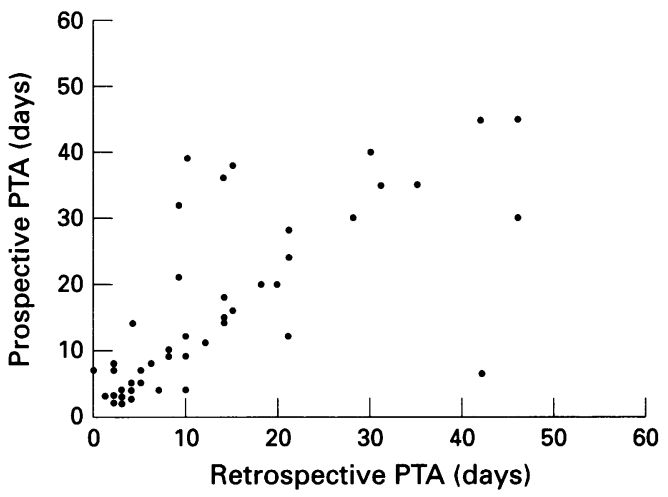

retrospective post-traumatic amnesia in greater detail for cases with shorter durations of post-traumatic amnesia.

No significant difference in duration of post-traumatic amnesia was found between prospective and retrospective groups using a paired samples $t$ test $(t=1.02$, df $65, \mathrm{P}=$ 0.31 ) or the non-parametric Wilcoxon matched pairs signed ranks test $(z=0.57, P$ $=-0.57$ ).

The Spearman correlation coefficient between prospective and retrospective measures $(r=0.87$ ) was highly significant (table 2). The Spearman correlation between prospective and retrospective post-traumatic amnesia remained high when post-traumatic amnesia was divided into bands according to the classifications of Russell ${ }^{1}$ and Jennett and

Table 2 Spearman correlations between prospective and retrospective measures of posttraumatic amnesia (days) whether not "banded" or classified as given in table 1

\begin{tabular}{llll}
\hline & $n$ & $r$ & Pvalue \\
\hline Not banded & 66 & 0.87 & $<0.001$ \\
A & 76 & 0.81 & $<0.001$ \\
C & 76 & 0.75 & $<0.001$ \\
C & 76 & 0.77 & $<0.001$ \\
\hline
\end{tabular}

Table 3 Spearman correlations ( $n$ ) between Glasgow coma scale score (GCS) or days of loss of consciousness (LOC) and prospective (GOAT)/retrospective (interview) measures of post-traumatic amnesia (days) whether not "banded" or classified into "bands" as given in table 1

\begin{tabular}{llrrrr}
\hline & & Not banded & \multicolumn{1}{l}{$(A)$} & \multicolumn{1}{l}{$(B)$} & \multicolumn{1}{l}{$(C)$} \\
\hline GCS & GOAT & $-0.58(63)^{\star \star}$ & $-0.57(73)^{\star \star}$ & $-0.54(73)^{\star \star}$ & \multicolumn{1}{l}{$-0.53(73)^{\star \star}$} \\
& interview & $-0.48(64)^{\star \star}$ & $-0.53(74)^{\star \star}$ & $-0.42(74)^{\star \star}$ & $-0.39(74)^{\star \star}$ \\
LOC & GOAT & $0.76(63)^{\star \star}$ & $0.76(73)^{\star \star}$ & $0.69(73)^{\star \star}$ & $0.64(73)^{\star \star}$ \\
& interview & $0.65(64)^{\star \star}$ & $0.71(74)^{\star \star}$ & $0.62(74)^{\star \star}$ & $0.78(74)^{\star \star}$ \\
\hline
\end{tabular}

$\star \star P \leqslant 0.01$
Teasdale $^{15}$ (three bands), Van Zomeren and Van den Burg $^{16}$ (two bands), or the five banded classification (table 2).

It is possible that the accuracy of retrospective estimation of duration of post-traumatic amnesia alters with time since injury, such that retrospective recall of contemporaneous events several years later may be less accurate. This would mean that an association between retrospective asssessment of post-traumatic amnesia and time since injury would have been expected, but not with the prospective assessments which were carried out within days of the accident. ${ }^{14}$ In fact, Spearman correlations between time since injury (at retrospective assessment) and retrospective $(r=-0.066, \mathrm{P}$ $=0.30)$ or prospective $(r=-0.03, \mathrm{P}=$ $0 \cdot 18$ ) assessments of post-traumatic amnesia were small and not statistically significant and hence this variable does not seem important in this study. ${ }^{17}$

Both the Glasgow coma scale score and days of loss of consciousness have been used as indices of severity of head injury. ${ }^{515}$ In this study both prospective and retrospective measures of post-traumatic amnesia correlated highly with Glasgow coma scale score and days loss of consciousness (table 3 ). The correlations were greater with days loss of consciousness in all cases.

In nine out of the 66 patients in whom exact values for post-traumatic amnesia were obtained, prospective and retrospective estimates fell in different severity bands according to the widely used classification of Jennett and Teasdale. ${ }^{15}$ No obvious reasons for this were found after scrutiny of each individual patient. If post-traumatic amnesia had continued beyond the end of the original study the prospective assessment would be inaccurate, and a mismatch with the retrospective assessment would be expected. This possibility was explored by considering the date of entry of cases into the original study, the duration of post-traumatic amnesia assessed prospectively, and the date when data collection in the original study was stopped (August 1991). This did not disclose any patients in whom prospective assessment of post-traumatic amnesia could have been inaccurate in this way.

In six of these nine patients, prospectively (P) assessed post-traumatic amnesia was greater than retrospective (R), and the opposite was the case in the other three. In none of these paired comparisons was post-traumatic amnesia found to be relatively brief ( $<7$ days) using one method and suggestive of a very severe injury ( $>14$ days) using the other. The range of differences in estimation using the two methods was greater when $R>P$ (35-161 days) than when $P>R$ (7-29 days) in these nine patients. In one patient, the difference was very great (19 P $v 180 \mathrm{R})$; as a result of the accident this person had been medically retired, continued to see a psychologist because of emotional problems, but remained independent and able to drive. From our data it is not clear which estimate of post-traumatic amnesia is likely to be more accurate. More 
generally, it was not obvious which estimate was likely to be most accurate in these nine patients when outcome measures such as return to work were considered.

Duration of post-traumatic amnesia might have been overestimated in patients with very severe and persisting memory impairment, leading to potential mismatches between prospective and retrospective estimates. Wilson et $a l^{18}$ were able to distinguish amnesic patients, patients with a severe memory impairment, and patients in post-traumatic amnesia from controls using neuropsychological tests. In this study, no differences were found between the nine patients who fell in different bands of severity of post-traumatic amnesia and the remaining patients, on scores for delayed recall of prose passages ( $\mathrm{df} 62, t=$ $0.43, P=0.68)$ or delayed recall of the Rey figure ( $\mathrm{df} 62, t=0.9, \mathrm{P}=0.36$ ) obtained six months after injury. When considering the entire sample, 10 patients with very severe impairment of new learning were found when assessed six months after injury. This impairment was defined as zero delayed recall of prose passages or of the Rey figure. ${ }^{19}$ None of these patients showed any clinically significant mismatch between prospective and retrospective assessments of post-traumatic amnesia. In two patients post-traumatic amnesia was greater than three months using both methods; four patients were not traceable for retrospective assessment, and in four patients an exact assessment of duration of post-traumatic amnesia retrospectively was not possible. In these last four patients all were in extremely severe bands whether prospective or retrospective methods were used. ${ }^{15}$

Relations between post-traumatic amnesia and outcome have been explored in many studies. In this study, retrospective and prospective measures of post-traumatic amnesia were compared against information about the patients' emotional problems, return to work, ability to cope with work, change in dependency as regards accommodation and care attendance requirements obtained from patients and their relatives, and subjective perception of stress reported by relatives (table 4 ). These outcome data were obtained at the time of the retrospective assessment. Duration of

Table 4 Spearman correlations between indices of outcome at the time of the retrospective assessment and measures of severity of injury (no of patients). Duration of post-traumatic amnesia was banded according to the classification of fennett and Teasdale ${ }^{15}$

\begin{tabular}{|c|c|c|c|c|}
\hline & $G C S$ & $L O C$ & $\begin{array}{l}\text { Prospective } \\
\text { PTA }\end{array}$ & $\begin{array}{l}\text { Retrospective } \\
\text { PTA }\end{array}$ \\
\hline \multirow{3}{*}{$\begin{array}{l}\text { Months working } \\
\text { since accident } \\
\text { Change in work } \\
\text { responsibility } \\
\text { Hours paid work/week } \\
\text { (if working) } \\
\text { Ability to cope with }\end{array}$} & $-0.09(68)$ & $-0.25(68)^{\star}$ & $0.36(70)^{\star \star}$ & $-0.38(69)^{\star \star \star}$ \\
\hline & $0 \cdot 16(33)$ & $-0.31(33)$ & $-0.39(33)^{\star}$ & $-0.32(33)$ \\
\hline & $0 \cdot 17(36)$ & $-0.11(36)$ & $-0.01(36)$ & $-0.00(36)$ \\
\hline $\begin{array}{l}\text { work } \\
\text { Hours of care }\end{array}$ & $-0.28(36)$ & $0.31(36)$ & $0 \cdot 29(36)$ & $0.36(36)^{\star}$ \\
\hline $\begin{array}{l}\text { Hours of care } \\
\text { attendance } \\
\text { Independent }\end{array}$ & $0.27(75)^{\star}$ & $0.35(75)^{\star \star}$ & $0.36(77)^{\star \star \star}$ & $0.34(76)^{\star \star \star}$ \\
\hline $\begin{array}{l}\text { accommodation } \\
\text { Emotional problems }\end{array}$ & $-0 \cdot 10(76)$ & $0 \cdot 14(76)$ & $0 \cdot 19(78)$ & $0 \cdot 25(77)^{\star}$ \\
\hline $\begin{array}{l}\text { (patient) } \\
\text { Stress in relative or }\end{array}$ & $-0.25(68)^{\star}$ & $0 \cdot 10(74)$ & $0 \cdot 24(76)^{\star}$ & $0.37(75)^{\star \star \star}$ \\
\hline carer & $-0.22(70)$ & $0.23(71)$ & $0.29(72)^{\star}$ & $0.32(71)^{\star \star}$ \\
\hline
\end{tabular}

${ }^{\star} \mathrm{P}<0.05 ;{ }^{\star \star} \mathrm{P}<0.01 ;{ }^{\star \star \star} \mathrm{P}<0.001$.

GCS = Glasgow coma scale score; LOC $=$ days of loss of consciousness. post-traumatic amnesia was banded according to the criteria of Jennett and Teasdale ${ }^{15}$ to maximise the potential sample size. Correlations were similar for retrospective and prospective measures in terms of size and number of significant associations. Subjective report of hours of paid work if working was not significantly associated with either measure of post-traumatic amnesia. Significant correlations were more commonly found with either measure of post-traumatic amnesia than with other measures of severity of injury, such as Glasgow coma scale score or days of loss of consciousness.

With the classification of Jennett and Teasdale ${ }^{15}$ there was a total of 11 of 16 statistically significant correlations (table 4 ) between retrospective or prospective measures of posttraumatic amnesia and psychosocial outcome measures. Using the classification of Van Zomeren and Van den Berg ${ }^{16}$ there were six of 16 and using the five banded classification eight of 16 . Correlations were statistically significant for three questions (months working since accident, hours of care attendance, and emotional problems in the patient) for both estimates of post-traumatic amnesia and all three methods of banding. There seemed to be little difference in the size of significant correlations between banding methods (range $0 \cdot 20-0 \cdot 44)$.

\section{Discussion}

This study examined the relations between prospective and retrospective methods of assessing post-traumatic amnesia. The findings do not support the assumption in earlier studies that assessment of duration of posttraumatic amnesia by prospective means is more accurate. The high correlation between post-traumatic amnesia assessed prospectively by GOAT and estimated retrospectively by an independent observer in this study, gives validity to retrospective interview as an accurate method of estimating duration of post-traumatic amnesia. In addition, in this study, the range of post-traumatic amnesia was truncated as it was always greater than one day; this means that the correlation between retrospective and prospective assessments is likely to be lower than if the entire range of post-traumatic amnesia was studied. ${ }^{20}$ The overall correlation of 0.87 is respectable if compared with the reliability quotients of widely used neuropsychological tests such as the Wechsler memory scale-revised general memory $(0 \cdot 81)^{21}$ or measures of activities of everday living such as the Barthel test $(0.93) .^{22}$

Note that we do not advocate the use of inexperienced staff as assessors of post-traumatic amnesia for clinical purposes. Given assessment by an experienced clinician, more accurate estimations of post-traumatic amnesia would be anticipated. However, for the purposes of this research study a very inexperienced interviewer was used. This adds to the robustness of the findings and lends further weight to the use of a retrospective method.

The highly significant correlations between 
other measures of severity of injury (Glasgow coma scale score and days loss of consciousness) and both methods of assessing duration of post-traumatic amnesia further add to the validity of the retrospective method. The scattergrams show that large differences between retrospective and prospective estimates can occur when post-traumatic amnesia is very long (fig 1). In such patients it may not be as clinically important to know the exact duration of post-traumatic amnesia because the very long duration necessarily classifies the head injury as extremely severe.

An exact retrospective estimate of posttraumatic amnesia was not possible in 12 of the 79 patients, but in 10 of these 12 , it was possible to judge whether it lasted for days, weeks, or months. In this way they could be put in one of the severity bands. Six of these 12 patients had a post-traumatic amnesia of more than 72 days as measured by the GOAT. When post-traumatic amnesia is as long, it is usually impractical to assess its duration daily by the GOAT, and here prospective values could be relatively inaccurate.

It is important and encouraging that both measures of post-traumatic amnesia were significantly associated with indices of outcome such as work, dependency, and emotional difficulties. The fact that there was little difference between prospective/retrospective indices and these everyday measures of outcome again support the validity of retrospective estimation.

It is also evident that both measures of posttraumatic amnesia were superior to other measures of severity of head injury in terms of association with psychosocial outcome. This reinforces the view that post-traumatic amnesia is currently the "gold standard" with respect to prediction of outcome after traumatic head injury. The correlations between outcome measures and post-traumatic amnesia are nevertheless fairly low, even though they are statistically significant. In part, this is to be expected because of the difficulty in measuring outcome in terms of psychosocial issues. In addition, variability will arise because of prognostic factors which are not directly related to post-traumatic amnesia but which affect outcome; examples of these are preinjury neurological or psychiatric history, alcohol abuse, and, after injury, carer support and provision of neurorehabilitation. ${ }^{23}$

For the clinician, this study validates estimation of the duration of post-traumatic amnesia retrospectively at interview. This is a more practical method than using a daily test contemporaneously. For research purposes, the study shows that retrospective assessment of post-traumatic amnesia can be as useful as the GOAT because both methods can be used by an independent investigator.

Appendix 1 The Galveston Orientation and Amnesia Test form

Name: ............................ Date of test:

Age: ...................... Sex: $M / F$

Day of the week: S M T W TH F S
Date of birth: Time: .......... AM . ... PM Diagnosis: Date of injury:

\section{GALVESTON ORIENTATION AND AMNESIA} TEST (GOAT)

1. What is your name? (2)

Error Points

When were you born? (4)

Where do you live? (4)

2. Where are you now? (5) city (5) hospital (unnecessary to state name of hospital)

3. On what date where you admitted to this hospital? (5)

How did you get there? (5)

4. What is the first event you can remember after the injury? (5) Can you describe in detail (e.g. date, time, companions) the first event you can recall after injury? (5)

5. What is the last event you can remember before the injury? (5) Can you describe in detail (e.g. date, time, companions) the last event you can recall before injury? (5)

6. What time is it now? ( 1 for each $\frac{1}{2}$ hour removed from correct time to max. of 5)

7. What day of the week is it? ( 1 for each day removed from correct day)

8. What day of the month is it? ( 1 for each day removed from correct date to max. of 5)

9. What is the month? ( 1 for each month removed from correct month to max. of 15)

10. What is the year? (10 for each year removed from correct year to max. of 30)

Total Error Points

Total Goat Score (100 total error points)

Appendix 2 Questionnaire establishing landmarks to estimate post-traumatic amnesia retrospectively

POST-TRAUMATIC AMNESIA

Question 1, 2, 3, 4 to be filled in before the interview Question 4, 5 and final PTA to be completed at interview

1. Date of injury:

2. A \& E: ............................................... Hospital

ICU: ..................................................... Hospital from .................. to ................. (........ days)

NSU: .................................................... Hospital from ................ to ................. (........ days)

DGH: ................................................. Hospital

Rehab. Unit: ............................................ Hospital from ................. to ................. (........ days)

3. Date of discharge (going home): ...................

4. Special events: $\quad$.............. (birthday)

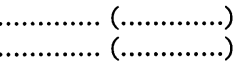

5. Do you remember

being taken to hospital

being in casualty

being in intensive care unit

being on the ward NSU/DHG/rehab

being taken to other hospital

going home from hospital

special event (birthday/Xmas)

PTA $=\ldots \ldots \ldots . .$. hours ........... days .......... months

This study was funded by the King Edward Hospital Fund for London. Grateful thanks are due to $\mathrm{Dr} G$ Dunn of the Department of Biostatistics, Institute of Psychiatry, London, for comments on statistical analysis. 
1 Russell WR. Cerebral involvement in head injury. Brain 1932;55:549-603.

2 Editorial. The best yardstick we have. Lancet 1961;ii: 1445-6.

3 Russell WR, Smith A. Post-traumatic amnesia in closed head injury. Arch Neurol 1961;5:16-29.

4 Shores EA, Marosszeky JE, Sandanam J, Batchelor J. Preliminary validation of a clinical scale for measuring duration of post traumatic amnesia. Med $\mathcal{F}$ Aust 1986; 144:569-72.

5 Brooks DN. Cognitive deficits. In: Rosenthal M, Griffiths ER, Bond MR, Miller JD, eds, Rehabilitation of the adult and child with traumatic brain injury. 2nd ed. Philadelphia FA Davis, 1990:163-78.

6 Bisihara SN, Partridge FM, Godfrey HPD, Knight RG Post-traumatic amnesia and Glasgow coma scale related to outcome in survivors in a consecutive series of patients with severe in survivors in a consecutive series of patients

7 Wilson JTL, Teasdale GM, Hadley DM, Wiedmann KD Lang D. Post-traumatic amnesia: still a valuable yardLang D. Post-traumatic amnesia: still a valuable yard-
stick. $\mathcal{F}$ Neurol Neurosurg Psychiatry 1993;56:198-201.

8 Forrester G, Encel J, Geffen G. Measuring post-traumatic amnesia (PTA): an historical view. Brain Inj 1994;8: amnesia

9 Russell WR, Nathan PW. Traumatic amnesia. Brain 1946; 69:280-300.

10 Schacter DL, Crovitz HF. Memory function after closed head injury. Cortex 1977;13:150-76.

11 Levin HS, O'Donnell VM, Grossman RG. The Galveston orientation and amnesia test. F Nerv Ment Dis 1979; 167:675-84.

12 Artiola I Fortuny L, Briggs $M$, Newcombe F, Ratcliffe G,
Thomas C. Measuring the duration of post-traumatic amnesia. I Neurol Neurosurg Psychiatry 1980;43:377-9.

13 Gronwall D, Wrightson P. Duration of post-traumatic amnesia after mild head injury. $\mathcal{F}$ Clin Neuropsychol 1980; 2:51-60.

14 Greenwood RJ, McMillan TM, Brooks DN, Dunn G, Brock D, Dinsdale S, et al. Effects of case management after severe head injury. $B M \mathcal{F}$ 1994;308:1199-205.

15 Jennett B, Teasdale G. Management of head injuries. Philadelphia: F A Davis, 1981

16 Van Zomeren AH, Van Den Berg W. Residual complaints of patients two years after severe head injury. $\mathcal{F}$ Neurol Neurosurg. Psychiatry 1985;48:21-8.

17 Norusis MJ. SPSS for Windows: base system users guide release 6.0. Chicago: SPSS Inc, 1993:303-10.

18 Wilson BA, Baddeley A, Shiel A, Patton G. How does post-traumatic amnesia differ from amnesic syndrome and chronic memory impairment? Neuropsychological Rehabilitation 1992;2:231-43.

19 Lezak MD, Neuropsychological assessment. 3rd ed. Oxford: Oxford University Press, 1955.

20 Anastasi A. Psychological testing. 5th ed. New York: MacMillan, 1982:123-5.

21 Wechsler D. Wechsler memory scale-revised. New York: The Psychological Corporation, Harcourt Brace Jovanovich, 1984

22 Wade DT. Measurement in neurological rehabilitation. Oxford: Oxford University Press, 1993.

23 McMillan TM, Greenwood RG. Head injury. In: Greenwood RJ, Barnes M, McMillan TM, Ward CD, eds. Neurological rehabilitation. Edinburgh: Churchill Livingstone, 1993:437-50.

\section{NEUROLOGICAL STAMP}

\section{Pedanius Dioscorides (born about AD40, died about AD90)}

Little is known of Dioscorides' life except that he served as a surgeon and military doctor for the Emperor Nero. On expeditions he gained a knowledge of botany and wrote a five volume book on pharmacology, De Materia Medica.

More than 600 plants and 1000 drugs were described in this pharmacopea, which remained the standard medical text until the 17th century. His notes on the plants include their habitat, methods of preparation, and medicinal use of the drugs they contained. Many of the common and scientific plant names in use today originate from Dioscorides. The yam family Dioscoreaceae is named after him. Preparations from the boiled root of the wild yam Dioscorea villosa were taken by Indian women to relieve the pains of childbirth and were recommended as a diuretic, emetic, expectorant, and remedy for colic and muscle spasms. Southern black people esteemed it especially as a treatment for rheumatism. Steroid-like substances have been found in Dioscorea villosa and related species. Various Dioscorea species were an important source of diosgenin used in the manufacture of birth control pills and certain other steroid drugs. The steroid-like properties of wild yam may account for its effectiveness in treating rheumatism and similar inflammatory diseases.

Dioscorides was probably the first to use willow to reduce fever and pain - the bark and leaves are rich in salicin, a glucoside closely related to acetylsalicylic acid. $\mathrm{He}$ prescribed mandragora wine as an anaesthetic agent and a remedy for insomnia and pain.

Dioscorides is honoured on an Algerian stamp published in 1963 (Stanley Gibbons 416, Scott 306) to commemorate the second Arab Medical Congress. A 13th century painting is reproduced showing Dioscorides delivering a lecture on medical plants. He is holding a mandrake (Mandragora). The original picture is preserved at the Topkapu Sarayl Muzesi of Istanbul.

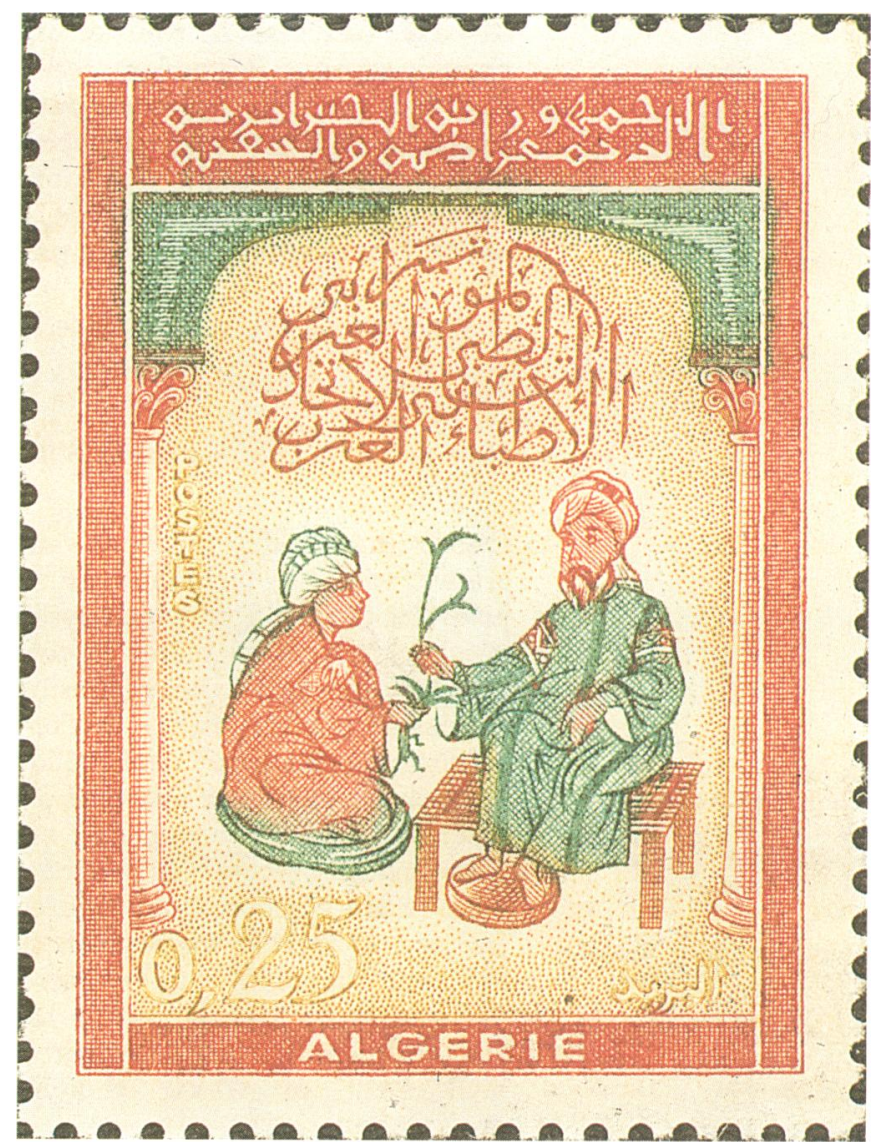

L F HAAS 